\title{
PREPARATION AND IN VITRO EVALUATION OF FAST RELEASE DIAZEPAM SUPPOSITORIES FOR FEBRILE SEIZURES
}

\author{
ASEEL ALSAMMAN*, MOHAMMAD OTHMAN \\ Department of Pharmaceutical Technology, Faculty of Pharmacy, Damascus University, Damascus, Syria. \\ Email: alsammanaseel@gmail.com
}

Received: 23 May 2017, Revised and Accepted: 10 June 2017

\section{ABSTRACT}

Objective: The objective of this study was to optimize the best formula for fast release suppositories of diazepam.

Methods: Suppositories were prepared by fusion method using Witepsol H15 as oleaginous base, polyethylene glycol as a water-soluble polymer, and Poloxamer 188 as water miscible base. All suppositories were evaluated for physical characteristics, in vitro drug release and kinetic models. The effects of incorporating Tween 80 as a non-ionic surfactant, propylene glycol as a cosolvent, and effervescent pair on the release rate of diazepam from suppositories were investigated. Differential scanning calorimetry and Fourier transform infrared spectrometry were used to characterize physical mixtures of diazepam and the different used bases.

Results: Many formulations of diazepam have been prepared and in vitro evaluated. PEG suppositories released diazepam more efficiently than poloxamer and witepsol suppositories. The including of an effervescent pair in the formulation of suppositories greatly enhanced the release of diazepam. The addition of tween 80 to witepsol suppositories, PG to poloxamer suppositories, increased the rate and extent of diazepam release.

Conclusion: Fast release of diazepam has been obtained from suppositories containing the effervescent pair (formula F3), which also have good physical properties.

Keywords: Diazepam, Suppositories, Polyethylene glycol, Poloxamer 188, Witepsol H15, Tween 80, Propylene glycol, Effervescent pair.

(C) 2017 The Authors. Published by Innovare Academic Sciences Pvt Ltd. This is an open access article under the CC BY license (http://creativecommons. org/licenses/by/4. 0/) DOI: http://dx.doi.org/10.22159/ajpcr.2017.v10i9.20162

\section{INTRODUCTION}

Diazepam is a long-acting benzodiazepine with anticonvulsant, sedative, and anxiolytic properties [1]. It is rapidly absorbed, enters the brain quickly and interrupts cerebral seizures of epilepsy within seconds to minutes. In general, diazepam, which is given intravenously, is the drug of choice for the emergency treatment of prolonged febrile seizures. However, it can only be administered in a hospital setting. Therefore, it is not an ideal medication to be given in the community by nonmedical personnel. Rectal formulations not only enable caregivers (parents, family) to treat uncontrolled seizures immediately but may also be administered by a physician when intravenous access is not possible. Rectal diazepam solutions have not been used widely because of the tendency to leak out of the rectum, which can lead to inaccurate dosing and treatment failure [2]. Diazepam in a conventional suppository is well absorbed, but its absorption is slow because of the slow release of the drug from the suppository bases. Studies have been conducted in an effort to determine how to increase the diazepam release rate from suppositories. The objective of this research was to develop the most effective rapid-release diazepam suppository formulations.

\section{MATERIALS AND METHODS}

\section{Materials}

The following materials were used: Diazepam (FIS- FABBRICA ITALIANA SINTETICI S.P.A, Milano, Italy), polyethylene glycol (PEG) (PEG 400, PEG 4000) (Riedel-De Haen Ag seelze-Hannover, Germany), Witepsol H15 (Dynamit Nobel, Leverkusen, Germany), Tween 80 (Riedel-De Haen Ag seelze-Hannover, Germany), Poloxamer 188 (Sigma-Aldrich, Germany), and Sodium phosphate (Sigma-Aldrich, Germany). Propylene glycol (PG) (Ineos. Belgium), Citric acid (Scharlab, Spain), and Sodium bicarbonate (Scharlab, Spain).

\section{Preparation of diazepam suppositories}

Suppositories containing $2 \mathrm{mg}$ of diazepam were prepared by the fusion method using different hydrophilic (PEG, Poloxamer 188) and lipophilic (Witepsol H15) bases. The bases were melted using a water bath. Diazepam powder was added with stirring until a homogeneous mixture was produced, and the mixture was poured into the metal suppository mold (each one of $1 \mathrm{ml}$ capacity) and was left to cool.

The value of the displacement factor (f) (a measure of how much base is displaced by a unit weight of an API), was calculated for the formula containing an effervescent pair, using the following equation [3].

$$
\mathrm{f}=\frac{100(\mathrm{E}-\mathrm{G})}{\mathrm{G} \cdot \mathrm{x}}+1
$$

Where $\mathrm{E}$ is the weight of the blank suppository containing only base, $\mathrm{G}$ is the weight of the suppository containing an effervescent pair in a known concentration, and $\mathrm{x}$ is the effervescent pair content of the suppository in weight percentage.

The suppository base weight was calculated using the following equation [3].

$$
\mathrm{TM}=\mathrm{E}-\sum_{\mathrm{i}=1}^{\mathrm{n}} \mathrm{fl} . \mathrm{s} 1
$$

Where TM is the suppository base to be weighed, E is the calibration constant of the mold, $\mathrm{f}$ is the displacement factor of each component, and $\mathrm{S}$ is the weight of each component (Table 1 ). 
Table 1: Composition of solid suppository formulations

\begin{tabular}{|c|c|c|}
\hline Formula & Diazepam (mg/suppository) & Suppository composition \\
\hline F1 & 2 & PEG $400050 \%+$ PEG $40050 \%$ \\
\hline F2 & 2 & PEG 4000 50\% + PEG 1500 35\% + PEG 400 15\% \\
\hline F4 & 2 & Poloxamer $188100 \%$ \\
\hline F5 & 2 & Poloxamer $18870 \%$ + PG 30\% \\
\hline F6 & 2 & Poloxamer 188 50\% + PG 50\% \\
\hline F7 & 2 & Witepsol $\mathrm{H}_{15} 100 \%$ \\
\hline F8 & 2 & Witepsol H ${ }_{15}^{10} 95 \%$ + Tween $805 \%$ \\
\hline F9 & 2 & Witepsol H $1590 \%$ + Tween $8010 \%$ \\
\hline
\end{tabular}

*Effervescent pair is composed of citric acid $138 \mathrm{mg}$ and $\mathrm{NaHCO}_{3} 62 \mathrm{mg}$, PEG: Polyethylene glycol

\section{Evaluation of the prepared diazepam suppositories} Weight variation

About 20 suppositories were weighed individually, and the average weights were determined. Up to two suppositories could deviate from average weight by more than $5 \%$ but not more than $10 \%$ [4].

\section{Content uniformity}

About 5 suppositories were selected randomly from each formula and assayed for the drug content. A suppository was added to $50 \mathrm{~mL}$ of phosphate buffer solution, $\mathrm{pH} 6.8$, then melted with gentle heating and shaking in an ultrasonic water bath (PHYLO, USH-10D Italy) at $37^{\circ} \mathrm{C}$. The volume was adjusted to $100 \mathrm{~mL}$ with phosphate buffer. Then, $2 \mathrm{~mL}$ was taken, and the volume was again adjusted with phosphate buffer to $10 \mathrm{~mL}$. The ultraviolet (UV) absorbance of the final solution was measured spectrophotometrically at $\lambda$ max $230 \mathrm{~nm}$ against a blank phosphate buffer solution [5]

\section{Mechanical strength/crushing test}

The test was used to measure the mass (in kilograms) that a suppository can bear without breaking. The suppository was positioned in an upright position, and increasing weights are placed on it until it loses its structure and collapses. The purpose of the test was to verify that the suppository can be transported under normal conditions and administered to the patient. A good result was at least 1.8-2 kg pressure [5]

\section{Disintegration test}

The disintegration test was achieved to determine whether the suppositories disintegrate within the prescribed time period. Each disintegrating device was placed in a beaker with a minimum capacity of $4 \mathrm{l}$, filled with water. The beaker was fitted with a slow stirrer and a support that holds the device vertically $90 \mathrm{~mm}$ below the water surface so that it can be inverted without emerging from the water. Water was maintained at a temperature of $36-37^{\circ} \mathrm{C}$ as the immersion fluid. The test was performed on three suppositories from each formula [6], using disintegration tester (COPLEY type: NE4-COPD: UK`NG42JY).

\section{Determination of melting range}

Many suppository bases and medicated suppositories are mixtures, and so do not have a precise melting point, that is why melting range or melting zone is the term often preferred by some rather than melting point. A number of different techniques are used to study melting behavior, including the open capillary tube, the U-tube, and the drop point methods [5].

The test was done using (BUCHI melting point $\mathrm{B}=540$ ) [5].

\section{Suppository penetration test}

The temperature was adjusted to that required for the test $\left(37^{\circ} \mathrm{C}\right)$. The suppository was placed in the device and the penetration rod gently moved into the appropriate place. The device holding the suppository and penetration rod was inserted into the constant temperature bath and a stopwatch was started. When the penetration rod drops through the softened suppository, the time was recorded [5]. The test was done on three suppositories from each formula using penetration tester (Erweka PM3).

\section{In vitro release of diazepam from solid suppository bases}

The USP rotating paddle dissolution apparatus (Pharma Test PT-DT7, Germany) was used at $37 \pm 0.5^{\circ} \mathrm{C}$ and $50 \mathrm{rpm}$ for the in vitro release studies of diazepam from solid suppositories. The release test was done for 45 minutes in $500 \mathrm{ml}$ phosphate buffer solution, pH 6.8. Samples, each of $5 \mathrm{~mL}$, were withdrawn from the dissolution medium at specified time intervals $(5,10,15,20,25,30$, and 45 minutes) and replaced by fresh buffer. Wire sinker was used to prevent suppository from floating on the surface of the dissolution medium. The samples were filtered through Millipore filter (Pore size 0.45 Micron, Xiboshi, syringe filter, China) and analyzed spectrophotometrically at $230 \mathrm{~nm}$ against a blank phosphate buffer (U-1800 UV/visible spectrophotometer, HITACHI, Japan). Each release experiment was performed in triplicate [7]. The validation process was done for the analytical method.

\section{Kinetic analysis of release data}

To describe the release models, in vitro release data from solid suppositories were analyzed according to a zero-order kinetic model, a first-order release model, a diffusion controlled model (Higuchi model), a Hixson-Crowell release model, and a Korsmeyer-Peppas model. The model that consistently produced the highest correlation among the suppository preparations was used for the assessment of drug release rates [8]. For Peppas model, the results were illustrated depending on $\mathrm{n}$ values, when $(0.45<\mathrm{n}<0.89)$ means a non-Fickian diffusion and when $\mathrm{n}=0.45$ indicates Fickian diffusion (Higuchi model).

\section{Statistical analysis of the drug release profiles}

All the results were expressed as mean values \pm standard deviation. The difference between percentages of diazepam released at specified time intervals, from the different formulations, were statistically evaluated using Student t-test. For results interpretation, $p$ value was significant when $\mathrm{p}<0.05$

\section{Differential scanning calorimetry (DSC)}

DSC is one of the most unique tools to determine the interaction between the active pharmaceutical ingredient and the excipients [9]. Thermal properties of diazepam, PEG, Poloxamer, Witepsol $\mathrm{H}_{15}$ and the physical mixtures of diazepam and each of the used excipients were studied, on a DSC (Mettler Toledo, USA). Samples (4-5 mg) were accurately weighed $( \pm 0.01 \mathrm{mg})$ and heated in closed aluminum crimp cells at a rate of $10^{\circ} \mathrm{C} /$ minute under nitrogen steam, at a flux rate of $100 \mathrm{ml} /$ minute, over a temperature range from $25^{\circ} \mathrm{C}$ to $400^{\circ} \mathrm{C}$. Measurements in triplicate were performed.

\section{Fourier transform infrared spectrometry (FTIR)}

The vibrational spectrum of a molecule is considered to be a unique physical property and is a characteristic of the molecule. As such, the infrared spectrum can be used as a fingerprint for identification by a comparison of the spectrum from an "unknown" with previously recorded reference spectra [10]. 
Table 2: Physical characterization of the tested suppositories

\begin{tabular}{|c|c|c|c|c|c|c|}
\hline Formula & Weight (g) \pm SD & Drug content (\%) & Hardness (kg) & Melting range $\left({ }^{\circ} \mathrm{C}\right)$ & $\begin{array}{l}\text { Liquefaction } \\
\text { time (min) }\end{array}$ & $\begin{array}{l}\text { Disintegration } \\
\text { time (min) }\end{array}$ \\
\hline F1 & $1.29 \pm 0.007$ & $96 \pm 2$ & $2 \pm 0.1$ & $37-42$ & $18.1 \pm 0.14$ & $13.15 \pm 0.21$ \\
\hline F2 & $1.32 \pm 0.004$ & $95.7 \pm 0.92$ & $2.9 \pm 0.11$ & $40-45$ & $19.17 \pm 0.15$ & $14.33 \pm 0.05$ \\
\hline F3 & $1.39 \pm 0.007$ & $99.9 \pm 0.14$ & $2.7 \pm 0.11$ & $36-42$ & $3.3 \pm 0.25$ & $4.3 \pm 0.05$ \\
\hline $\mathrm{F} 4$ & $0.99 \pm 0.009$ & $97.5 \pm 0.71$ & $3.5 \pm 0.11$ & $45-55$ & $61.2 \pm 0.32$ & $42.75 \pm 0.35$ \\
\hline F5 & $1.064 \pm 0.008$ & $100 \pm 0.1$ & $2.7 \pm 0.11$ & $40-45$ & $28.25 \pm 0.35$ & $17 \pm 0.1$ \\
\hline F6 & $1.129 \pm 0.01$ & $100.9 \pm 2.6$ & $2.1 \pm 0.23$ & $32.5-36$ & $25.75 \pm 0.35$ & $3 \pm 0.1$ \\
\hline F8 & $1.075 \pm 0.004$ & $92 \pm 0.71$ & $3.6 \pm 0.1$ & $30-35$ & $6 \pm 0.1$ & $14.75 \pm 0.35$ \\
\hline F9 & $1.081 \pm 0.006$ & $96 \pm 0.5$ & $3.3 \pm 0.11$ & $29-34$ & $5.3 \pm 0.07$ & $12.1 \pm 0.14$ \\
\hline
\end{tabular}

\section{RESULTS AND DISCUSSION}

\section{Physical properties of the tested suppositories}

The weight variations for all suppositories were found to be within the acceptable range $(<5 \%)[6]$. The drug content of suppositories, for each formulation, was in the acceptable range (85-115\%) [4]. The mechanical strengths were more than $1.8 \mathrm{~kg}$ for all the formulations, showing optimum hardness for handling and transportation [5]. The melting ranges of all the investigated suppositories comply with the pharmacopeia requirements. The addition of Tween 80 leads to depression of the melting range of suppositories. The softening times of all suppositories were within 30 minutes and that comply with the pharmacopeia limits [5], expect for F4 (Poloxamer 100\%) which had taken about $1 \mathrm{hr}$ to soften or liquify, and that is maybe due to the gelling characteristics of Poloxamer 188 (thermo sensitive polymer) [11]. The disintegration time was within 30 minutes for Witepsol H15 suppositories and within 60 minutes for hydrophilic base suppositories, and that complies with the pharmacopeia limits (Table 2) [6].

In vitro release rate of diazepam from water-soluble and water miscible bases

The dissolution profiles of diazepam from PEG formulas (F1, F2, and F3) are shown in Fig. 1. Statistical analysis revealed a significant difference $(\mathrm{p}<0.05)$ between formulas (F1, F2), at $5 \mathrm{~min}$, and between (F2, F3) at 5,10 minutes with respect to the studied release rates. Diazepam has reached its maximum release in about 15 minutes in formulas 1 and 2 . The fastest release formula was $\mathrm{F} 3$, which contained an effervescent pair, in which diazepam reached its maximum release in about 5 minutes. The high release rate of diazepam from PEG suppositories may be due to both low affinity of the drug to the base and water solubility of the base, which allows the drug to be released by both diffusion and erosion mechanisms [12]. The dissolution of very slightly soluble substances, like diazepam, is usually the rate-limiting step in the absorptive process, therefore as much as we can enhance the dissolution rate, the absorption will be improved [13]. The effervescent pair enhanced the release rate for (F3), so according to rates of diazepam release from PEG suppositories, the results were as follows: F3 > F1 > F2.

For Poloxamer based suppositories, the dissolution profiles are shown in Fig. 2. Statistical analysis revealed a significant difference $(p<0.05)$ between formulas. Releasing rate of diazepam from Formula 4 (with $100 \%$ Poloxamer 188) as a base was lower and slower than that from other Poloxamer formulas (F5, F6) which contained (30\% and 50\%) PG, respectively. That is because Poloxamer in formula 4 was gelatinized and has not dissolved in the dissolution medium, but in the presence of PG which has a hygroscopic property, water uptake was increased, and a hydrophilic matrix was formed [8]. That is why the $\mathrm{d}$ results were as follows: F6 > F5 > F4

\section{In vitro release rate of diazepam from oleaginous bases (Witepsol} H15)

The dissolution profiles of diazepam from fatty base suppositories (F7, F8, and F9) are shown in Fig. 3. Statistical analysis revealed a significant difference $(\mathrm{p}<0.05)$ between formulas. Diazepam could not be released from Formula 7 (with 100\% Witepsol H15), due to the strong affinity

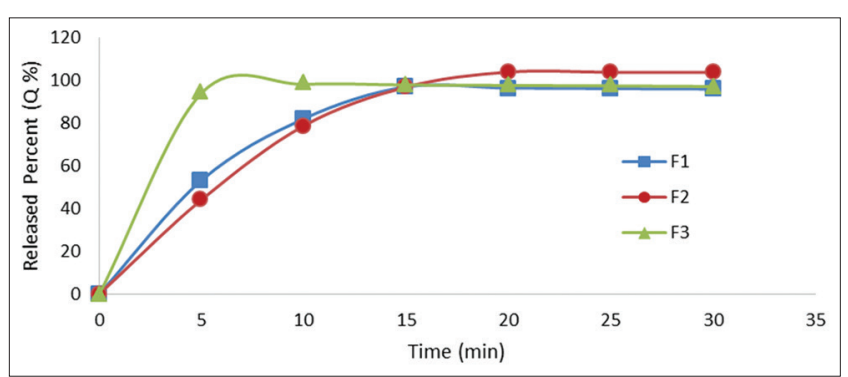

Fig. 1: Release profiles of diazepam from various hydrophilic PEG bases

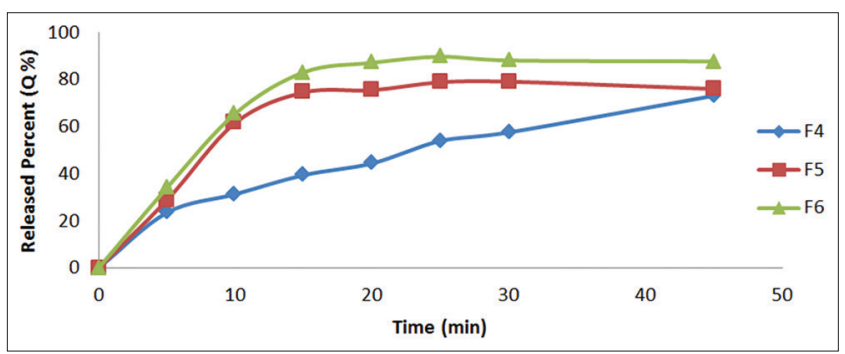

Fig. 2: Release profiles of diazepam from various Poloxamer 188 bases

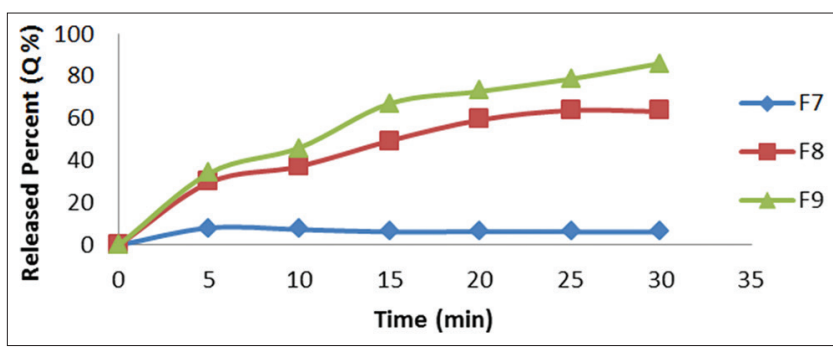

Fig. 3: Release profiles of diazepam from various Witepsol $\mathbf{H}_{1}$ bases

of the drug to the lipophilic base ( $\log p=2.82$ for diazepam [14], and diazepam is classified as a Class II according to Biopharmaceutics Classification System BCS [15]). Which result in a hindrance of diazepam molecules migration into the dissolution medium [16]. When Tween 80 , which is a hydrophilic non-ionic surfactant (HLB = 15), was incorporated, the dissolution rate was enhanced. Percent of drug released increased on increasing Tween 80 concentration. That is because Tween 80 has lowered the interfacial tension and increased dispersion of suppository base in the dissolution medium [17]. However, the release rates were still slower than that observed with PEG based suppositories. Results were according to the release rates of diazepam as follows: F9 > F8 > F7. 
Table 3: In vitro release kinetic parameters of diazepam from the studied suppositories

\begin{tabular}{|c|c|c|c|c|c|c|}
\hline Formula & Zero-order $\left(\mathbf{r}^{2}\right)$ & First-order $\left(\mathbf{r}^{2}\right)$ & Higuchi $\left(r^{2}\right)$ & Hixon $\left(r^{2}\right)$ & Peppas (n) & Peppas $\left(r^{2}\right)$ \\
\hline F1 & 0.967 & 0.938 & 0.99 & 0.948 & 0.560 & 0.99 \\
\hline F2 & 0.91 & 0.851 & 0.958 & 0.871 & 0.633 & 0.961 \\
\hline F3 & \multicolumn{6}{|c|}{ Diazepam was released completely in about 5 minutes } \\
\hline F4 & 0.964 & 0.879 & 0.993 & 0.914 & 0.517 & 0.994 \\
\hline F5 & 0.695 & 0.62 & 0.8 & 0.645 & 0.54 & 0.84 \\
\hline F6 & 0.822 & 0.75 & 0.9 & 0.775 & 0.61 & 0.916 \\
\hline F7 & \multicolumn{6}{|c|}{ Diazepam was not released during the test period } \\
\hline F9 & 0.941 & 0.9 & 0.974 & 0.909 & 0.53 & 0.98 \\
\hline
\end{tabular}

$\left(r^{2}\right)$ correlation coefficient

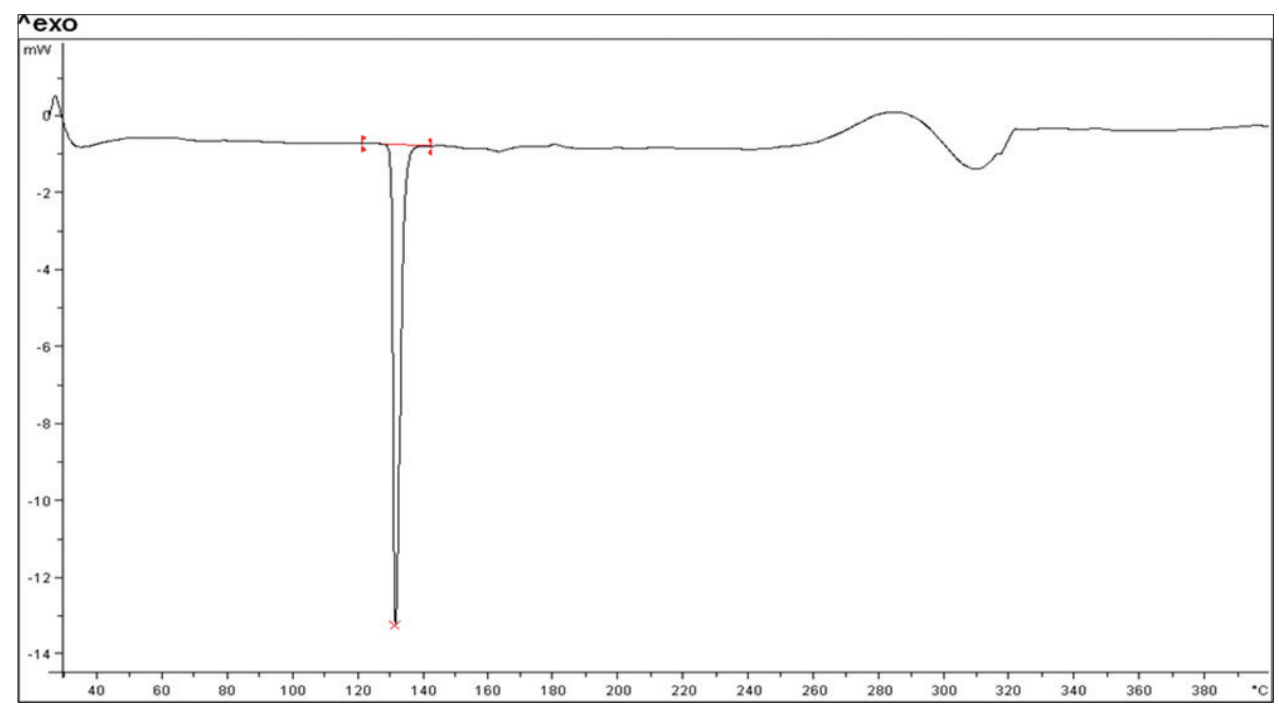

Fig. 4: Differential scanning calorimetry curve of pure diazepam

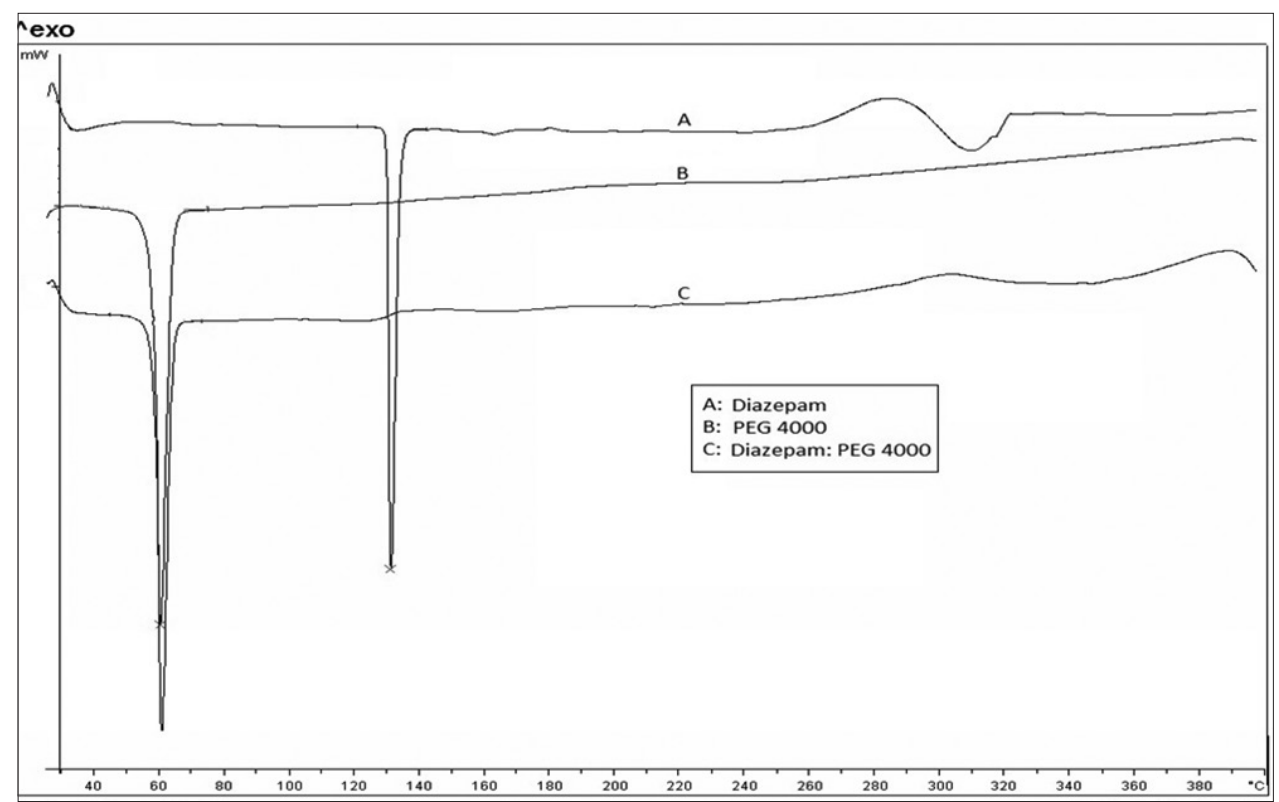

Fig. 5: Differential scanning calorimetry curve of diazepam, polyethylene glycol (PEG) 4000, diazepam-PEG 4000 physical mixture

\section{Kinetic analysis results}

From Table 3, according to $\mathrm{r}^{2}$ and $\mathrm{n}$ values, the release kinetic model of all suppositories complies with Higuchi and Cross Mayer Peppas. In all formulas, $\mathrm{n}$ is bigger than 0.45 and smaller than 0.89 , this indicates a non-Fickian diffusion [18]. Therefore, the release has occurred probably by diffusion, swelling, and erosion.
DSC results

The DSC thermograms of diazepam Fig. 4 showed a single sharp endothermic peak at $131.51^{\circ} \mathrm{C}$ corresponding to the melting point of diazepam. Concerning the obtained thermogram from PEG 4000, a wide endothermic melting peak at $60.32^{\circ} \mathrm{C}$ was observed, this wideness could be due to the variation in the molecular weights of the polymer. DSC curves 


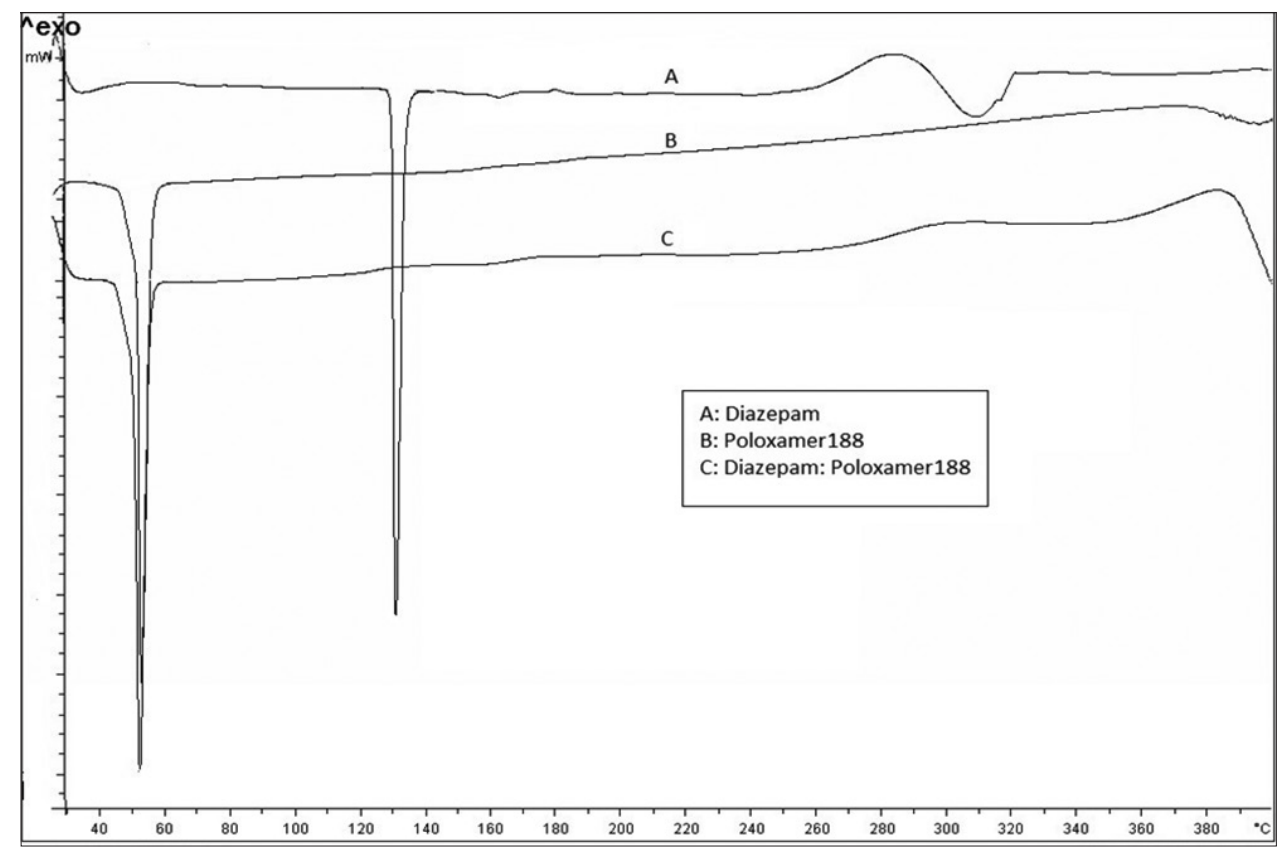

Fig. 6: Differential scanning calorimetry curve of diazepam, Poloxamer 188, diazepam-Poloxamer 188 physical mixture

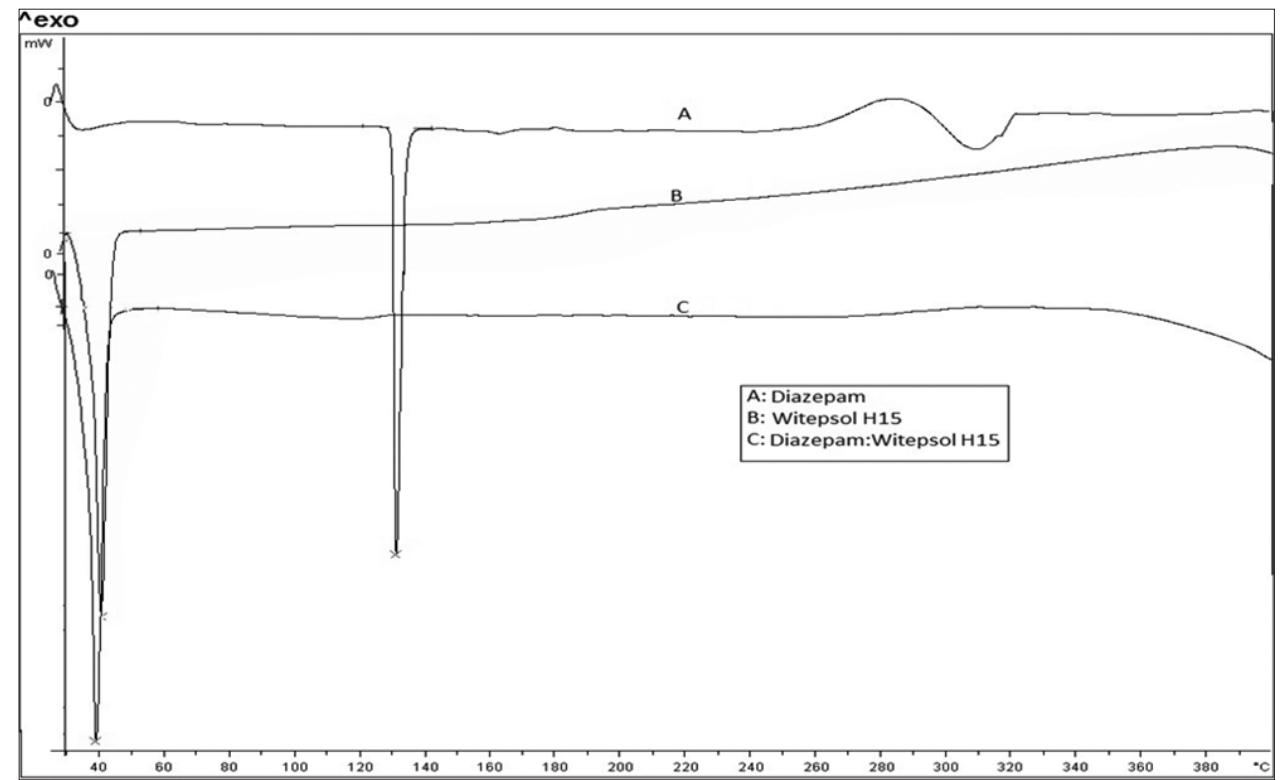

Fig. 7: Differential scanning calorimetry curves of diazepam, Witepsol $\mathrm{H}_{15}$, diazepam-witepsol $\mathrm{H}_{15}$ physical mixture

of the physical mixture of diazepam with PEG 4000 base Fig. 5 showed only one endothermic peak at $60.32^{\circ} \mathrm{C}$ correlating with the melting of PEG with the absence of the endothermic peak of diazepam. This result suggests that crystalline diazepam has become in the amorphous state or in molecularly dispersed structure in PEG [19]. The same result was found when diazepam was in a physical mixture with Poloxamer 188, where the physical mixture of diazepam with Poloxamer base showed only one endothermic peak at $53.04^{\circ} \mathrm{C}$, correlating with the melting of Poloxamer with an absence of the endothermic peak of diazepam (Fig. 6). The thermogram of the physical mixture of diazepam with Witepsol H15 Fig. 7 showed also only one endothermic peak corresponding to the melting of Witepsol, with the absence of diazepam peak. That is maybe because that diazepam was completely soluble in the Witepsol base [20].

\section{FTIR spectrometry results}

This is the basis of computer-based spectral searching. In the absence of a suitable reference database, it is possible to give a basic interpretation
Table 4: The most important functional groups in diazepam chemical formula and their infrared absorption

\begin{tabular}{ll}
\hline Assignment & Wavenumber $\left(\mathbf{c m}^{-\mathbf{1}} \mathbf{)}\right.$ \\
\hline C=O carbonyl stretching & 1681 \\
C=C stretching & 1313 \\
Aromatic in plane C-H bend & 1127 \\
Out of plane C-H bend & 836.9 and 786.7 and 738.7 and \\
& 705.5 \\
C-N stretching & 813.6 \\
\hline
\end{tabular}

of the spectrum from first principles, leading to characterization, and possibly even identification of an unknown sample [10]. This is based on the fact that structural features of the molecule, whether they are the backbone of the molecule or the functional groups attached to the molecule, producing characteristics and reproducible absorptions in 


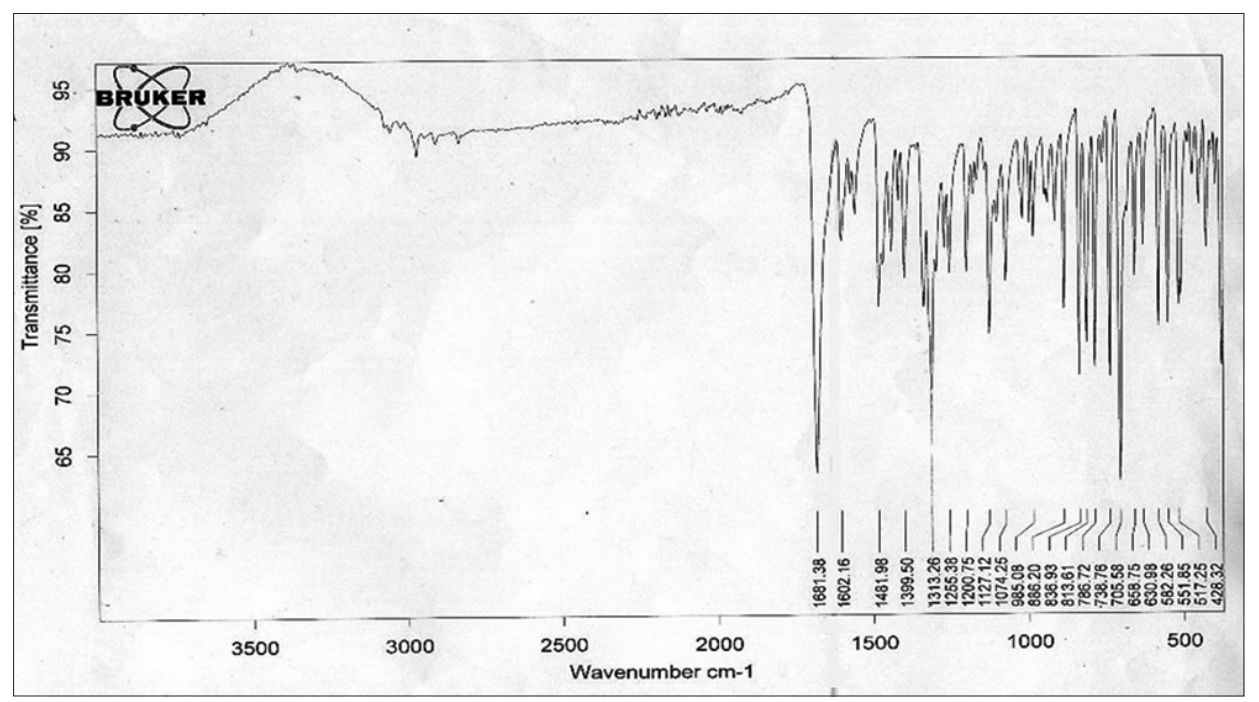

Fig. 8: Fourier transform infrared spectra of diazepam

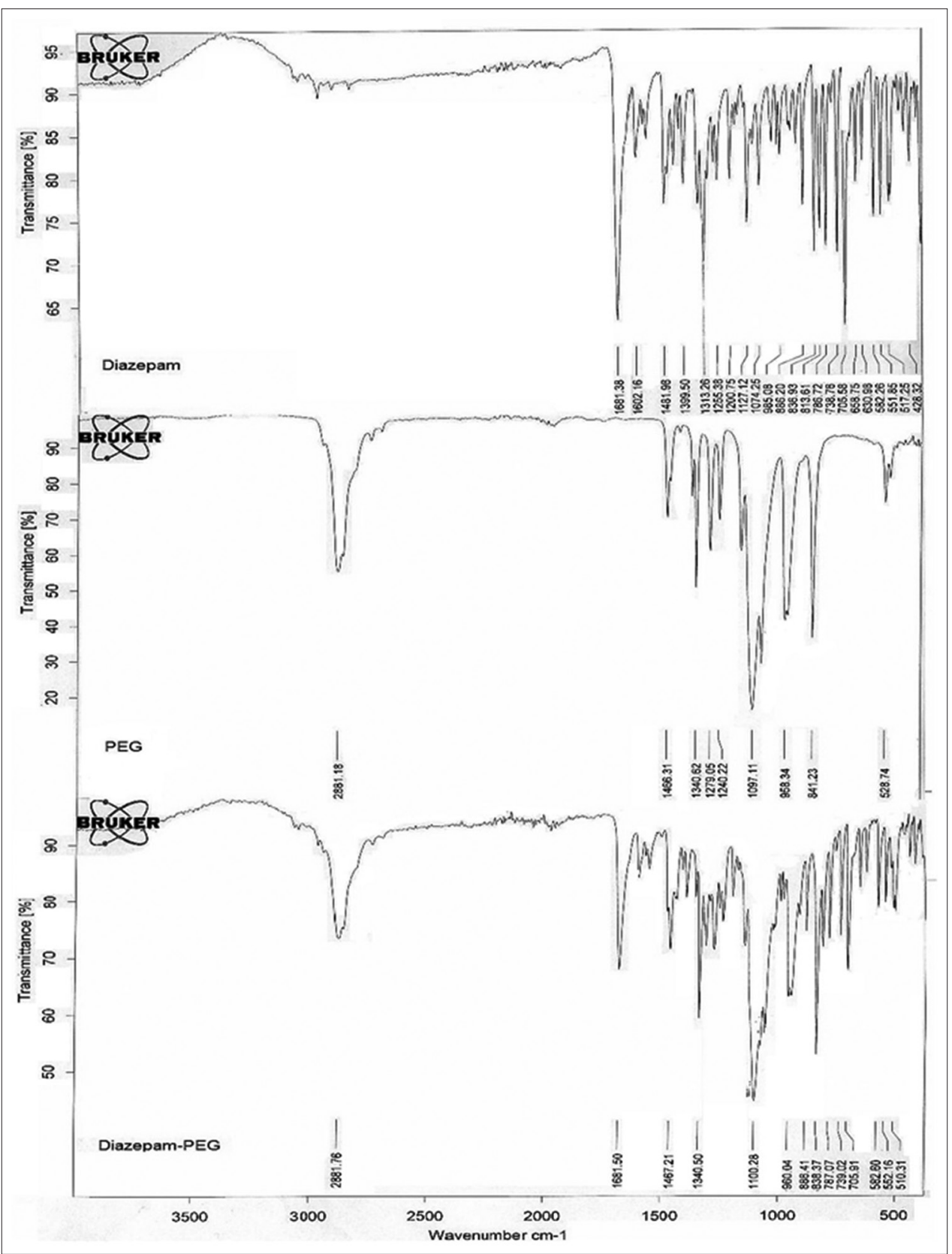

Fig. 9: Fourier transform infrared spectra of diazepam, PEG 4000, and their physical mixture, respectively 


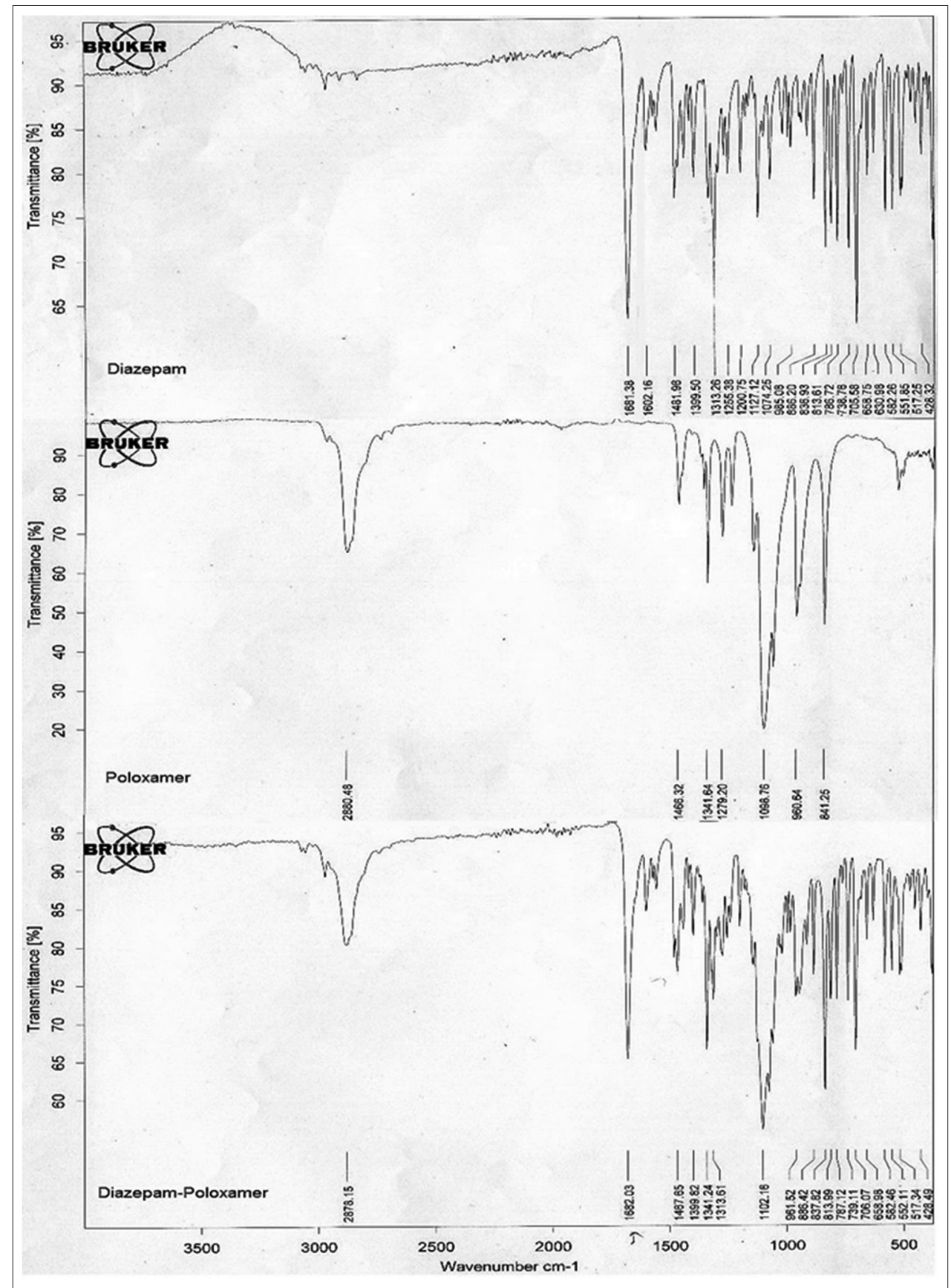

Fig. 10: Fourier transform infrared spectra of diazepam, Poloxamer 188, and their physical mixture, respectively

the spectrum. This information can indicate whether the backbone consists of linear or branched chains, as it is possible to determine if there is an unsaturation and/or aromatic rings in the structure. Finally, it is possible to deduce whether specific functional groups are present (Table 4) [21].

The FTIR spectrum of diazepam is shown in Fig. 8, and the most important functional groups are mentioned in Table 4 . The bands 1680 , $1605,1400,1320,740,700$, and $580 \mathrm{~cm}^{-1}$ appear to be characteristic of the 1, 4-benzodiazepine structure [22]. $\mathrm{C}=0$ stretch, a very strong infrared absorption band was observed about $1680 \mathrm{~cm}^{-1}$ in the spectra of diazepam $\mathrm{C}=\mathrm{N}$ stretch, a weak band in the infrared spectra. $\mathrm{CH}$ group vibrations, a methylene group at position 3 of the diazepine ring, has six modes of vibration, which can be described as symmetric and asymmetric stretching, a "scissors" deformation and wagging, twisting and rocking motions. The two stretching modes are usually found near 2850 and $2930 \mathrm{~cm}^{-1}$ in saturated aliphatic hydrocarbon groups. Aromatic $\mathrm{C}=\mathrm{C}$ stretching modes, the 5-phenyl-1, 4-benzodiazepines have both mono- and trisubstituted benzene rings, each of which has six aromatic $\mathrm{C}=\mathrm{C}$ stretching modes. Several of these are expected in the $1300-1600 \mathrm{~cm}^{-1}$ region [22].

The most characteristic bands of PEG 4000 (Fig. 9) are $3441 \mathrm{~cm}^{-1}$ which corresponds to $\mathrm{O}-\mathrm{H}$ stretching, $2878 \mathrm{~cm}^{-1}$ corresponds to $\mathrm{C}-\mathrm{H}$ stretching, $1343 \mathrm{~cm}^{-1}$ and $1464 \mathrm{~cm}^{-1}$ correspond to C-H bending. Finally, 1094,1240 , and $1279 \mathrm{~cm}^{-1}$ correspond to $\mathrm{O}-\mathrm{H}$ and $\mathrm{COH}$ stretching.

In the FTIR spectra of the physical mixture of diazepam and PEG 4000 (Fig. 9), all absorption bands of diazepam were observed with a small shifting at out of plane C-H bends from 836 to $838 \mathrm{~cm}^{-1}$, whereas in PEG spectrum, absorption band at $958 \mathrm{~cm}^{-1}$ has been shifted to $960 \mathrm{~cm}^{-1}$, 
absorption band at 1097 has shifted to $1100 \mathrm{~cm}^{-1}$ complying with $0-\mathrm{H}$ and $\mathrm{COH}$ stretching, and band shifting from $1466 \mathrm{~cm}^{-1}$ to $1467 \mathrm{~cm}^{-1}$ corresponding to $\mathrm{C}-\mathrm{H}$ bending. This may indicate the formation of hydrogen bonds between diazepam and PEG 4000.

The most characteristic bands of Poloxamer 188 (Fig. 10) are $2880 \mathrm{~cm}^{-1}$ which correspond to $\mathrm{C}-\mathrm{H}$ stretching, $1341 \mathrm{~cm}^{-1}$ and $1466 \mathrm{~cm}^{-1}$ correspond to $\mathrm{C}-\mathrm{H}$ bending, and 1098 and $1279 \mathrm{~cm}^{-1}$ corresponds to $\mathrm{O}-\mathrm{H}$ and $\mathrm{COH}$ stretching [23].

In the FTIR spectra of the physical mixture of diazepam and Poloxamer 188 (Fig. 10), all absorption bands of diazepam were observed with a small shifting (one degree) from 1681 to $1682 \mathrm{~cm}^{-1}$, and no difference in Poloxamer absorption bands has occurred.

\section{CONCLUSION}

To conclude, many formulations of diazepam have been prepared and in vitro evaluated diazepam physically interacted with PEG 4000, Poloxamer 188, and Witepsol H15 according to DSC studies. The including of an effervescent pair in the formulation of suppositories (F3) greatly enhanced the release of diazepam. Moreover, the addition of Tween 80 has a favorable role in increasing the drug release.

\section{REFERENCES}

1. Sweetman SC, editor. Martindale: The Complite Drug Reference. $36^{\text {th }}$ ed. London: The Pharmaceutical Press; 2009.

2. Fitzgerald BJ, Okos AJ, Miller JW. Treatment of out-of-hospital status epilepticus with diazepam rectal gel. Seizure 2003;12(1):52-5

3. Kalmár E, Lasher JR, Tarry TD, Myers A, Szakonyi G, Dombi G, et al. Dosage uniformity problems which occur due to technological errors in extemporaneously prepared suppositories in hospitals and pharmacies. Saudi Pharm J 2014;22(4):338-42.

4. British Pharmacopeial Commisssion. British Pharmacopoeia. London: The Stationery Office on Behalf of the Medicines and Healthcare Products Regulatory Agency (MHRA); 2013.

5. Allen LV Jr. Quality control of suppositories. Suppositories. $1^{\text {st }}$ ed. UK: The Pharmaceutical Press; 2008. p. 139-58.

6. Beck DC, editor. European Pharmacopeia. $7^{\text {th }}$ ed. Germany: Council of Europ; 2011. p. 255-65.

7. Dissolution Methods, Division of Bioequivalence, FDA; 2015. Available from: https://www.accessdata.fda.gov/scripts/cder/dissolution.
8. Moghimipour E, Dabbagh MA, Zarif F. Characterization and in vitro evaluation of piroxicam suppositories. Asian J Pharm Clin Res 2009;2(3):92-8.

9. Varshney HM, Chatterjee A. Release characteristics of zaltoprofen. Asian J Pharm Clin Res 2012;5(4):4-7.

10. Coates J. Interpretation of infrared spectra, a practical approach interpretation of infrared spectra, a practical approach. Encyclopedia of Analytical Chemistry. Chichester: John Wiley \& Sons Ltd.; 2000. p. 10815-37.

11. Seo YG, Kim DW, Yeo WH, Ramasamy T, Oh YK, Park YJ, et al. Docetaxel-loaded thermosensitive and bioadhesive nanomicelles as a rectal drug delivery system for enhanced chemotherapeutic effect. Pharm Res 2013;30(7):1860-70.

12. Hosny E. Formulation, in-vitro release and ex-vivo spasmolytic effects of mebeverine hydrochloride suppositories containing polycarbophil or polysorbate 80. Int J Pharm 1996;142(2):163-8.

13. Najmuddin M, Khan T, Aa M, Shelar S, Patel V. Enhancement of dissolution rate of ketoconazole by solid dispersion technique. Int $\mathrm{J}$ Pharm Pharm Sci 2010;2(3):132-6.

14. Shokri J, Nokhodchi A, Dashbolaghi A, Hassan-Zadeh D, Ghafourian T, Barzegar Jalali M. The effect of surfactants on the skin penetration of diazepam. Int J Pharm 2001;228(1-2):99-107.

15. Biopharmaceutics Classification System. Available from: http://www. tsrlinc.net/results.cfm.

16. Tanaka M, Kuwahara E, Takahashi M, Koyama O, Takahashi N, Yotsuyanagi T. Enhanced rectal absorption of amphotericin B lyophilized with glycyrrhizinate in rabbits. Biol Pharm Bull 1998;21(8):853-7.

17. Realdon N, Dal Zotto M, Morpurgo M, Franceschinis E. Effects of surfactant characteristics on drug availability from suppositories. Pharmazie 2008;63(6):459-63.

18. Samaha D, Shehayeb R, Kyriacos S. Modeling and comparison of dissolution profiles. Eur J Pharm Sci 2001;13:123-33.

19. Cwiertnia B. Solubility of selected derivatives of 1,4-benzodiazepin-2one in solid dispersions in PEG 6000. Acta Pol Pharm 2006;63(2):135-9.

20. Kaewnopparat N, Kaewnopparat S, Rojanarat W, Ingkatawornwong S. Enhanced release of diazepam from hollow-type suppositories. Int J Pharm Compd 2004;8(4):310-2.

21. Singh RR, Kumar A, Kaur R. FTIR analysis of some pills of forensic interest. Res J Pharm Biol Chem Sci 2013;4(4):708-12.

22. Neville GA, Shurvell HF. Fourier transform raman and infrared study of diazepam and four closely related 1,4-benzodiazepines. J Raman Spectrosc 1990;21(1):9-19.

23. Sadiq AA, Abdul-Rassol AA. Formulation and evaluation of silibinin loaded solid lipid nanoparticles for peroral use targeting lower part of gastrointestinal tract. Int J Pharm Pharm Sci 2014;6(1):55-67. 